\title{
ANALYZING THE SPATIAL DISTRIBUTION OF DRUMLINS: A TWO-PHASE MOSAIC APPROACH
}

\author{
By B. N. Boots and R. K. Burns
}

(Department of Geography, Wilfred Laurier University, Waterloo, Ontario N2L 3C5, Canada)

\begin{abstract}
Researchers have analyzed various properties of drumlins within individual drumlin fields in order to provide evidence to help in identifying the processes involved in drumlin formation. One property which has been examined is the spatial distribution of drumlins within a field. Traditionally, in such endeavours the individual drumlins have been represented as points and their distribution examined using techniques of point-pattern analysis. We suggest that not only is such a representation inappropriate at this scale, it also introduces statistical bias which makes the results of such analyses questionable. Consequently, we propose an alternative approach which involves representing individual drumlins as areal phenomena and considering their pattern as a two-phase mosaic. The advantages of such an approach are discussed and it is illustrated by applying it to two different drumlin fields.
\end{abstract}

RÉsumé. Analyse de la répartition spatiale des drumlins: une approche mosaïque à deux étapes. Des chercheurs ont analysé différentes propriétés des drumlins pour des champs particuliers de façon à dégager des caractéristiques utiles à l'identification des processus mis en oeuvre lors de leur formation. Une des propriétés traitée concerne leur répartition dans un champ. Habituellement, lors de tels essais les drumlins sont représentés comme des points et leur distribution est examinée à l'aide de l'analyse des caractéristiques des points. Nous proposons que non seulement une telle représentation est inadéquate à cette échelle, mais que de plus elle introduit un biais statistique

\section{INTRODUCTION}

By virtue of their smooth, distinctive shape, drumlins are amongst the most visible legacies of the Pleistocene glaciers. Consequently, they have been the subject of considerable research. However, despite this attention, much remains unknown about drumlins, in particular the conditions responsible for their formation. A comprehensive survey of the theories of formation proposed so far, together with a review of most other facets of drumi in research, has been given by Menzies (1979). In common with other areas of geomorphology, one aspect of drumlin research has been concerned with the spatial distribution and morphological characteristics of individual drumlins, since such evidence is useful both in the verification and modification of existing theories and in the propagation of new theories. With this goal in mind, it is important that we should be able to describe such features as succinctly as possible. In this paper we focus on the quantitative description of the spatial distribution of individual drumlins within a drumlin field. We begin with a critical review of existing methods and then propose and illustrate the use of an alternative approach.

\section{PREVIOUS APPROACHES}

Amongst the earliest studies of the within-field distribution of drumlins were those of Reed and others (1962), Vernon (1966), and Baranowski (1969), which involved measuring the spacing between individual druml ins (or more precisely between the length axes of individual drumlins). Although these techniques permitted the inclusion of a directional component in the analysis with measurements being made both parallel and perpendicular to the assumed direction of ice flow, they suffered from several shortcomings. First, as Smalley and Unwin (1968, p. 383) pointed qui rend contestables les résultats de cette analyse. C'est pourquoi nous proposons une approche différente qui fait intervenir la représentation d'un drumlin individuel comme un phénomène de surface en considérant leur caractéristiques comme une mosaïque à deux étapes. Les avantages d'une telle approche sont discutés et elle est mise en application pour deux différents sites de drumlins.

Zusammenfassung. Analyse der räumlichen Verteilung von Drumlins: ein zweiphasiges Mosaik-Verfahren. Forscher haben verschiedene Eigenschaften von Drumlins untersucht, mit dem Ziel, Aussagen zur Klärung der Prozesse bei der Drumlinbildung zu gewinnen. Eine dieser Eigenschaften ist die räumliche Verteilung von Drumlins innerhalb eines Feldes. Traditionsgemäss werden bei diesen Bemühungen die einzelnen Drumlins als Punkte dargestellt, deren Verteilung mit Verfahren der PunktmusterAnalyse untersucht wird. Wir vermuten, dass eine solche Darstellung in diesem Massstab nicht nur unangemessen ist, sondern dass sie auch statistische Unwägbarkeiten mit sich bringt, die das Ergebnis der Analysen frag würdig erscheien lassen. Wir schlagen daher ein anderes Vorgehen vor, bei dem einzelne Drumlins als flächenhafte Erscheinungen dargestellt werden, deren Muster als zweiphasiges Mosaik betrachtet wird. Die Vorteile eines solchen Verfahrens werden diskutiert; durch Anwendung auf zwei verschiedenen Drumlinfelder wird es erläutert.

out, the identification of the appropriate measurements is not always unambiguous. Further, since the result of such an analysis is a frequency distribution, no single summary measure is obtained for the spatial distribution. Although it is possible to compare such empirical frequency distributions with theoretical ones, this was not attempted, perhaps because an appropriate model distribution was not readily identifiable. In turn, this often resulted in subsequent qualitative interpretations of the empirical frequencies.

Dissatisfaction with these earlier approaches led to the adoption of the prevailing approach. This involves categorizing individual drumlins as points and analyzing the resulting patterns using techniques of point-pattern analysis. In drumlin research, the most frequently used procedures are quadrat analysis and nearest-neighbour analysis. Examples of the former range from standard applications in the work of Trenhaile (1971) to more sophisticated use in the block-size analyses of variance undertaken by Hill (1973), while the use of nearest-neighbour analysis is illustrated by Smalley and Unwin (1968) and Jauhiainen (1975). While each of these procedures has inherent general limitations which are present in most contexts (for a review of these for quadrat analysis in general see Rogers (1974), for block-size analysis of variance in particular see Pielou (1974, p. 98), and for nearest-neighbour analysis see Pinder and Witherick (1972) and De Vos (1973)), there are additional problems which arise in the analysis of the spatial distribution of drumlins. Most of these are inherent in the representation of a set of drumlins as a point pattern. First, the representation of objects as points when they themselves are not points requires that their physical sizes relative to the distances between them and the extent of the study area are so small that they can be conveniently ignored ( $\mathrm{Cl}$ iff and Ord, 1981, p. 86; Ripley, 1981, p. 3). It is dif- 
ficult to justify such a representation in the case of individual drumlins in a single field. Secondly, by representing the drumlins which are three-dimensional by points which are considered dimensionless, there is a considerable loss of information (Menzies, 1979, p. 338-39). In addition, druml in orientation is lost, thus precluding the inclusion of an explicit directional component in the analysis. Further, there is the problem of deciding at which location in the drumlin the point representing it should be placed. There is no agreement on this matter. Reed and others (1962) used a location midway along the length axis, while Smalley and Unwin (1968) took the stoss end of this axis, and $\mathrm{Hill}$ (1973) the point of intersection of the length and width axes; Trenhaile (1971, 1975) and Jauhiainen (1975), on the other hand, used the druml in summit. Further exacerbation of this problem is the occurrence of coalesced drumlins. Should they be represented as two points or one? The answer obviously involves a somewhat arbitrary decision by the researcher (see Hill, 1973, p. 231). Finally, the reduction of a druml in to a point produces an inhibition effect around each point thus truncating the 1 ower limit on the inter-point distances, since on average the distance between any two points cannot be less than the width of a drumlin. This effect has not been acknowledged in existing analyses, which have compared empirical patterns with model ones having no such lower limit on inter-point distances and which, on occasion, seem to have been chosen more for their availability than for their applicability. When the model pattern is a random one (i.e. the realization of an homogeneous planar Poisson point process), such a comparison will be biased in favour of indicating a more "dispersed than random" empirical pattern. Smalley and Unwin (1968, p. 387) implicitly recognized this problem when they noted that their random placement model produced results which would normally be interpreted as lying between uniformly spaced and random.

\section{THE TWO-PHASE MOSAIC APPROACH}

A two-phase (or binary) mosaic represents a planar region in which sub-regions (patches) occupied by a particular phenomenon alternate with unoccupied areas (gaps). The concept can be extended to $n$ phases and, consequently, mosaics can be used to represent a number of empirical circumstances (see Pielou, 1974, p. 166-93, [1975], p. 72-84). It is interesting to note that Hill (1973) used an n-phase mosaic approach, although he did not identify it as such, in which the phases were patches of different drumlin densities. Here we limit our attention to a two-phase mosaic, in which each druml in is considered as a patch. We suggest that there are certain advantages in representing spatial distributions of drumlins as mosaics rather than as point patterns. First, the representations of individual drumlins as two-dimensional objects is much more appropriate for analysis at the within-field scale. Such representations retain more information, although drumlin volume is still ignored. Amongst the information retained is drumlin orientation, which permits analysis of directional components in the spatial distribution. Also the problems of point 1ocation and coalesced drumlins are avoided.

As with empirical point patterns, empirical mosaics can be evaluated using theoretical structures. Following the precedents established so far, the most likely standard is a "random" (pure chance) two-phase mosaic. Intuitively, we might consider a "random" mosaic as the outcome of a "random" process which 1ocates the patches in the plane. Unfortunately, it has long been recognized that there is no unique random process of this kind (Kendall and Moran, 1963, p. 911). However, Pielou (1964) has suggested that a twophase mosaic could be regarded as random if the sequence of phases observed at equal intervals along a traverse through the pattern conforms to a simple, two-state Markov chain. This implies that the phase observed at any point depends only on the phase at the preceding point on the traverse. As Switzer (1965) pointed out, this condition is met only in mosaics formed by drawing a set of "random" lines in the plane (using the method described by Miles (1964)) and then independently assigning to each of the convex polygons so created a colour (black or white, say) with fixed probabilities b and $w$, respectively, with $b+w=1$. Such a mosaic (with $b=0.1$ ) is shown in Figure 1. Although it would be absurd to suggest that

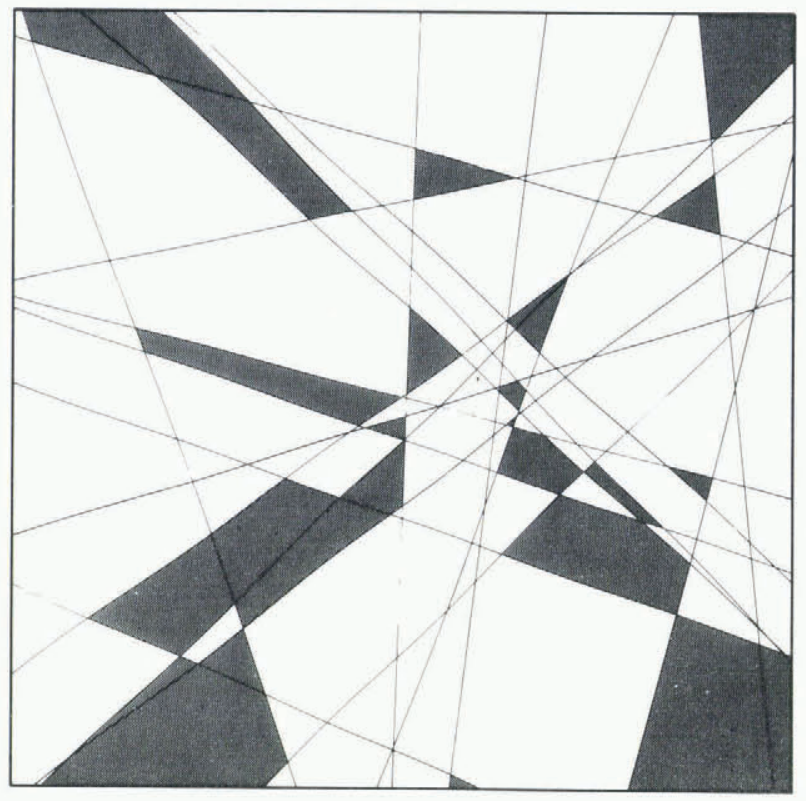

Fig. 1. A part of a random mosaic.

the conditions involved in the creation of this random mosaic occur in the real world, Pielou ([C1977], chapter 12) argued that this does not preclude the model's use as a standard by which to compare empirical patterns, especially if we suspect that such patterns may possess properties (e.g. the means and variances of the sizes of the phases) which are indistinguishable from those of the random mosaic. Such an assumption appears reasonable in the case of drumlins, if we assume that there is no overlapping of individual drumlins and that each druml in is independent of all other drumlins. It is possible that an empirical pattern may be random in other than an isotropic way. Pielou (1965) recognized two possibilities. Unidirectional randomness occurs if the sequence of phases gives a two-state Markov chain in only one direction. If sampling in any direction gives a two-state Markov chain but the transition probabilities vary with direction, the pattern is said to be anisotropically random (Moore, 1974). We might well expect such patterns for drumlins with respect to the assumed direction of ice flow.

The test for randomness in a mosaic has been given in detail by Pielou (1965, p. 911-14) and will only be summarized here. First, a direction, which is held constant for all traverses, is selected. In the illustrations below we use directions both parallel and perpendicular to the assumed ice-flow direction. Since we are testing for Markov properties, the traverse need only consist of two points. Pielou suggested that, in order to get the best representative coverage of the mosaic, a large number of short traverses, each of a pair of points, is preferable to a few long traverses. This is especially so when the mosaic is fine-grained (i.e. when the total length of inter-phase boundary in the mosaic is high), which is the case for drumlins. The results obtained from the traverses are 
tabulated as a matrix, $\left[\mathrm{m}_{j k}\right]=[\mathrm{M}]$. The test for randomness consists of deciding whether the $m_{j k}$ can be regarded as the same as those of successive pairs of a simple Markov chain with a transition probability matrix of the form $[P]$ where

$$
[P]=\left[\begin{array}{ll}
P_{1} & P_{2} \\
P_{1} & P_{2}
\end{array}\right] \text {. }
$$

Rielou showed that the maximum likelihood estimate, $\mathrm{P}_{1}$, of $\mathrm{P}_{1}$ may be obtained from

$$
\begin{aligned}
& m_{11} \hat{p}_{1}^{-1}-\underset{k \neq j}{-\sum_{j k}}\left(m_{j k}\right)\left(1-\hat{p}_{1}\right)^{-1}+ \\
& +\left(m_{22} a_{1}\right)\left[\left(\hat{P}_{1} a_{1}\right)+\left(a_{2}-a_{1}\right)\right]^{-1}=0
\end{aligned}
$$

where $a_{1}$, a $a_{2}$ are the elements of the 1 imiting vector (i.e. $a_{j}=$ probability that the first of a pair of sampling points is inthe $j$ th phase and is equal to the proportion of the study area covered by the $j$ th phase), and that an estimate, $\hat{p}_{1}$, of $p_{1}$ may be obtained from

$$
\hat{p}_{1}=a_{1}\left(1-\hat{p}_{1}\right) a_{2}{ }^{-1} \text {. }
$$

Further, the elements $d_{1 j k}$, of the matrix of expected transition frequencies, $\left[D_{1}\right]$ are given by

$$
\begin{aligned}
& d_{1_{j k}}=M a_{j} p_{k} \quad(j \neq k) \text { and } \\
& d_{1_{j k}}=M a_{j} P_{j} \quad(j=k)
\end{aligned}
$$

where $M=\sum_{j} \sum_{k} m_{j k}$.

Because of sampling errors, the row totals of $\left[\mathrm{D}_{1}\right]$ may not be equal to those of $[M]$. Thus, a second matrix, $\left[\mathrm{D}_{2}\right]$, can be constructed in which

$$
\begin{aligned}
& d_{2_{j k}}=M_{j} P_{k} \quad(j \neq k) \text { and } \\
& d_{2_{j k}}=M_{j} P_{j} \quad(j=k)
\end{aligned}
$$

where $M_{j}=\sum_{j} m_{j k}$.

It is $\left[\mathrm{D}_{2}\right]$ which is used in testing the goodness of fit to the matrix of observed frequencies, [M]. A chisquared test is used which has one degree of freedom for a two-phase mosaic.

\section{ILLUSTRATIONS}

The technique is applied to two drumlin fields. One is the Vale of Eden field previously examined by Smalley and Unwin (1968) using nearest-neighbour analysis. The other is a field in the Dundalk area of southern Ontario.

Figure 2 reproduced from Smalley and Unwin (1968) shows the Vale of Eden field they examined. The drum1 ins in this pattern were identified from $1: 25000$ topographic maps by means of contour patterns (Smalley and Unwin, 1968, p. 387). Approximately $7 \%$ of the study area is covered by drumlins. This value was obtained by direct measurement but, if the researcher prefers to avoid this tedious task, made especially more so by large fields, the proportions can be estimated (Pielou, [1975], p. 200). The pattern was sampled both parallel and perpendicular to the assumed ice flow, which was defined as the average azimuth of the orientation of the drumlins' long axes $\left(154^{\circ}\right)$.

Pielou (1965, p. 912) suggested that the length of such a traverse should be short enough for there to

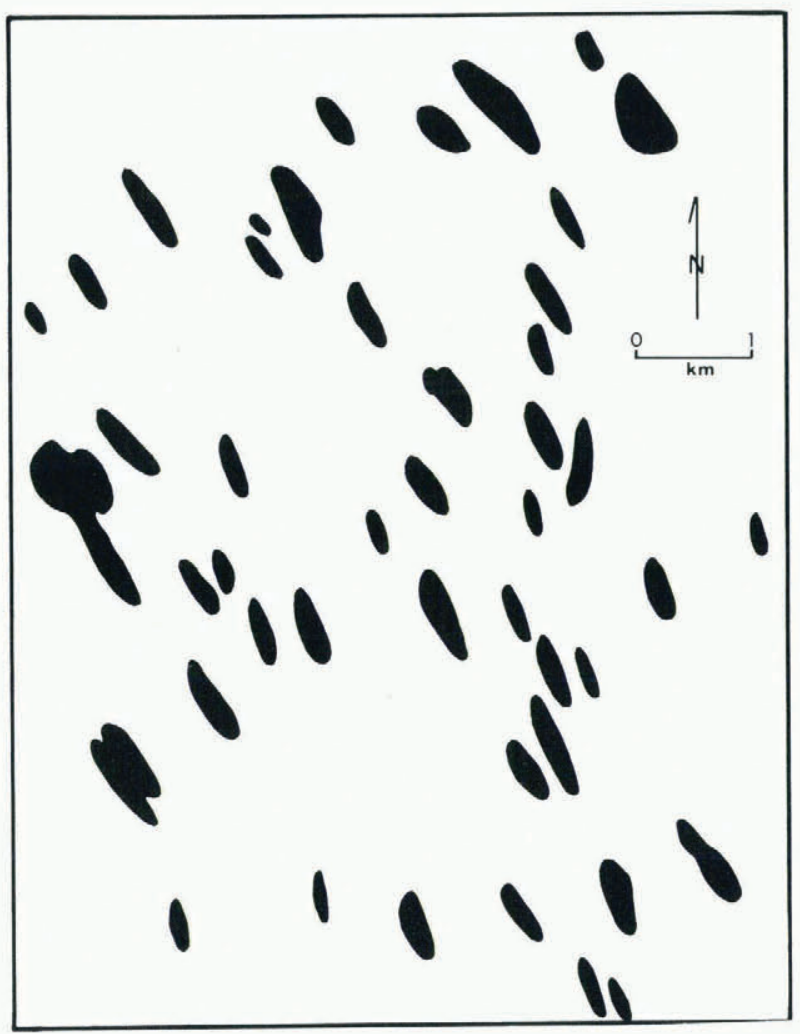

Fig. 2. Vale of Eden drumlin field analyzed by Smalley and Unwin (1968).

be pronounced dependence between the points forming the pair and long enough for most of the $m_{j k}(j \neq k)$ to form an appreciable fraction of the total. Our choice of traverse lengths was guided by this observation and the lengths used are such that there is a nonzero chance that the points in a pair may fall within a single drumlin. This was achieved by setting the length of a traverse equal to one-half of the average length of the drumlins' long axes $(327 \mathrm{~m})$ in the direction parallel to the assumed ice flow and at half that distance $(163.5 \mathrm{~m})$ perpendicular to the ice flow. Two sets of 150 points, each located at random in the study area, were then created. Each of these points was taken as the southernmost or westernmost point of a pair of points lying the specified distance apart in a direction of $154^{\circ}$ or $244^{\circ}$. The states (i.e. drumlin or non-drumlin) at each end of these traverses were recorded and are given in Table I. Subsequent analysis, summarized in Table I, shows that both in directions parallel and perpendicular to assumed ice flow the sampled frequencies are not significantly different from those expected for a random mosaic with the same proportion of drumlinized area.

The other drumlin field examined is located in the Dundalk area of southern Ontario (see Fig. 3). This field has not been described previously in the literature. Drumlins were identified by stereoscopic interpretation of air photographs at a scale of 1: 15840 followed by selective field checking. Initially, all features exhibiting some degree of elongation and positive local elevations were classified as drum1 ins. Subsequently, eskers and moraines were eliminated from the group. Approximately $6 \%$ of the study area is covered by drumlins. A part of this field is shown in Figure 4.

As in the previous analysis, the pattern was analyzed both parallel and perpendicular to the assumed direction of ice flow. However, since the drumlins in this field show greater variation in their orientation than those in the first area, it was decided to perform two sets of analyses. In the first of these 
TABLE I. VALE OF EDEN

$\left(a_{1}, a_{2}\right)(0.071,0.929)$

Parazlel to ice flow

(azimuth $154^{\circ}$ )

$\underset{\mathrm{D}}{\text { Phase at }} \mathrm{N} \underset{\mathrm{N}}{\mathrm{N}}$

\begin{tabular}{|c|c|c|c|}
\hline Phase & at & 4 & 6 \\
\hline S poi & & 7 & 133 \\
\hline$[P]$ & $=$ & $\begin{array}{l}.382 \\
.047\end{array}$ & $\begin{array}{l}0.618 \\
0.953\end{array}$ \\
\hline$\left[D_{1}\right]$ & $=$ & $\begin{array}{l}4.04 \\
5.54\end{array}$ & $\begin{array}{r}6.53 \\
132.89\end{array}$ \\
\hline$\left[\mathrm{D}_{2}\right]$ & $=$ & $\begin{array}{l}3.82 \\
6.57\end{array}$ & $\begin{array}{r}6.18 \\
133.43\end{array}$ \\
\hline
\end{tabular}

$x^{2}=0.043$

D Drumlinized.

N Not drumlinized.
Perpendicular to ice flow (azimuth $244^{\circ}$ )

Phase at $E \underset{N}{\text { point }}$

Phase at $0 \quad 006$

$\begin{array}{lll}\text { W point } \mathrm{N} & 7 & 137\end{array}$

[P] $=\quad \begin{array}{ll}0.000 & 1.000\end{array}$

$\left[D_{1}\right]=\quad 0.00 \quad 10.57$

$10.57 \quad 128.86$

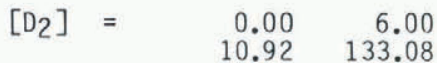

$x^{2}=1.159$

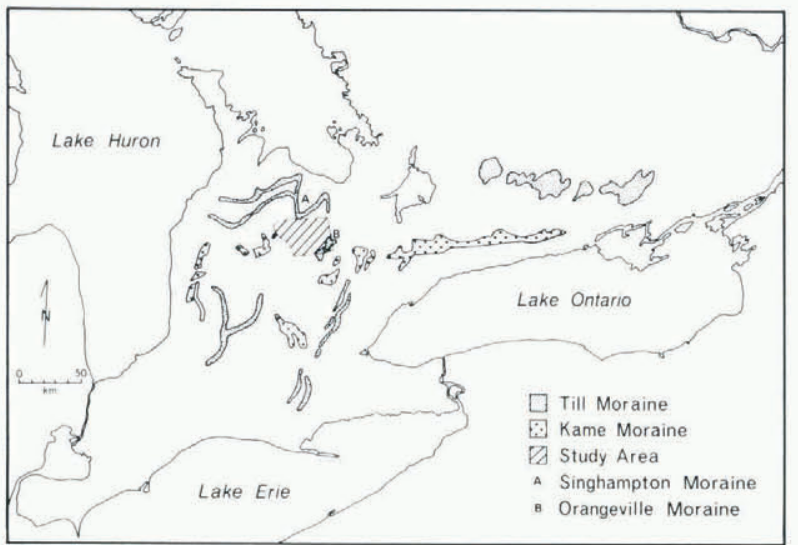

Eig. 3. Location of the Dundalk drumlin field (Canada. Dept. of Energy, Mines and Resources, 1972).

sets, the sampled directions were the mean drumlin azimuthal orientation $\left(157^{\circ}\right)$ and a direction orthogonal to this $\left(247^{\circ}\right)$, while in the second they were the modal orientation $\left(135^{\circ}\right)$ and $225^{\circ}$. In each case, the pattern was sampled using 150 short traverses. As in the previous illustration, the southern and western ends of the traverses were located at random in the study area and their lengths were equal to one-half of the average drumlin length $(230 \mathrm{~m})$ in the direction parallel to the assumed ice flow and one-quarter of the average drumlin length $(115 \mathrm{~m})$ in the direction perpendicular to the assumed ice flow. The resulting samples are shown in Tables II and III. For both directions, for both sets of analyses, the results again indicate that the pattern is not significantly different from a random mosaic.

\section{CONCLUDING COMMENTS}

We have presented a method of analyzing the within-field spatial distribution of drumlins which we think is both more appropriate and useful than ex isting methods. However, this does not mean that the new method could not be refined. In particular, some might question the choice of the random-line mosaic as an appropriate general random mosaic model for drumlins. This model was chosen, in part, because of its availability and analytical tractability. Of course, the technique does not preclude the use of

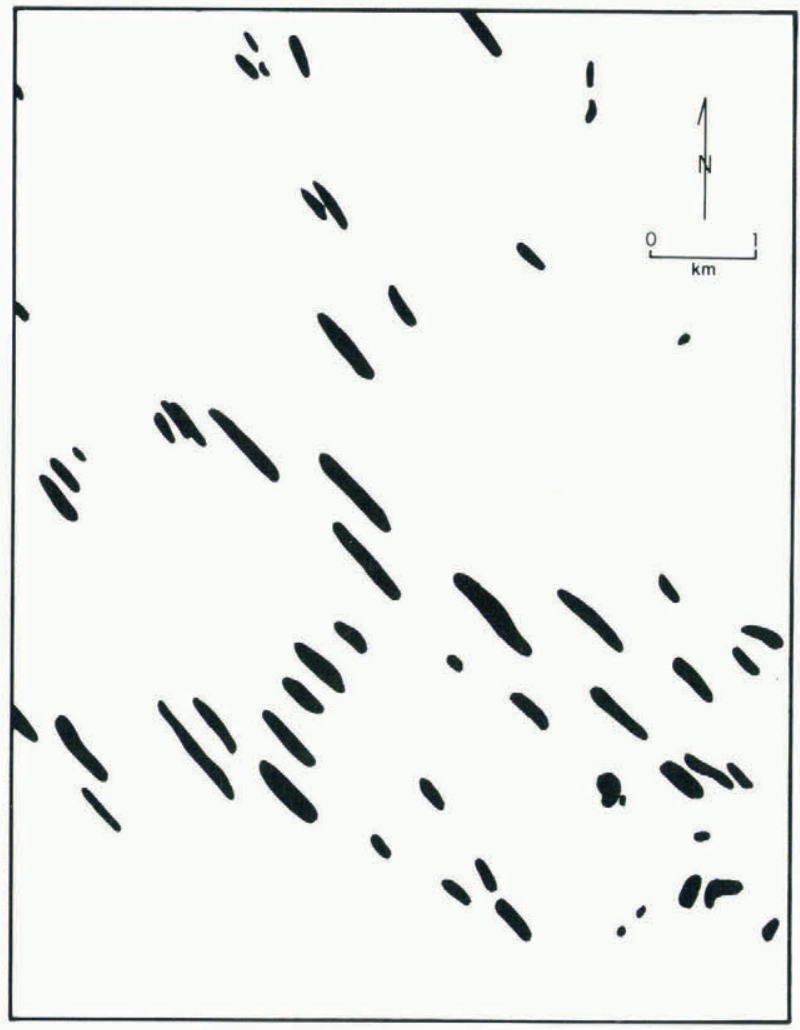

Fig. 4. A part of the Dundalk drumlin field.

other models, such as the random placement model of Smalley and Unwin (1968), as the random mosaic model. However, it is unlikely that such alternative models will possess properties which are as easily identified and described as the Markovian ones of the random-line mosaic. In such circumstances, we will have to resort to the use of a simulation approach as, for example, Diggle (1981) did in his study of patterns of heather as two-phase mosaics. In general, such an approach involves simulating the process believed to have been responsible for generating the empirical pattern and then using a Monte Carlo testing procedure. In summary, this would involve measuring one or more properties of the empirical pattern ( $P_{2}$ would 
TABLE II. DUNDALK AREA, MEAN ORIENTATION

$$
\left(a_{1}, a_{2}\right)(0.063,0.937)
$$

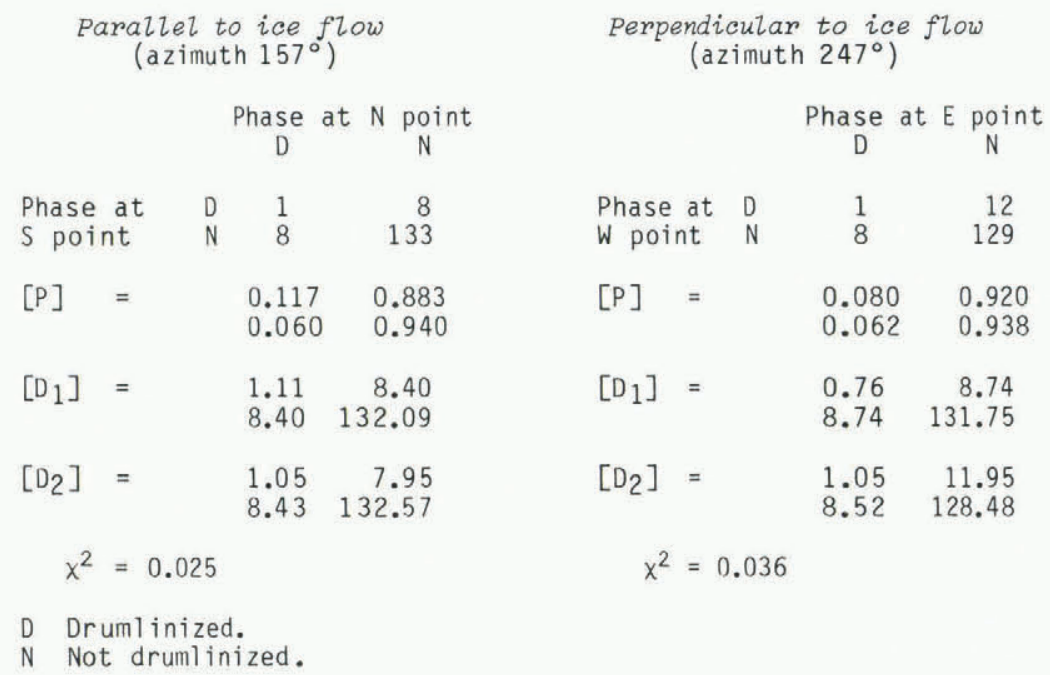

TABLE III. DUNDALK AREA, MODAL ORIENTATION $\left(a_{1}, a_{2}\right)(0.063,0.937)$

Parallel to ice flow

(azimuth $135^{\circ}$ )

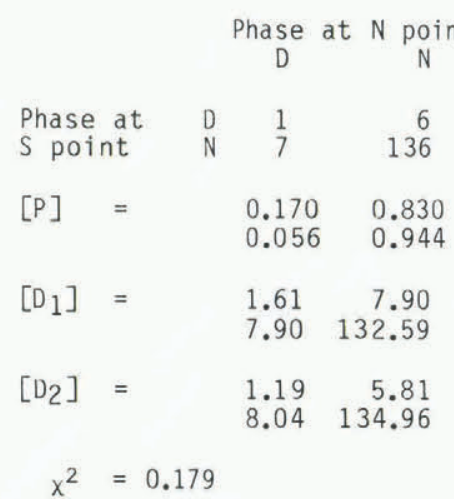

D Drumlinized.

N Not drumlinized. seem a likely choice) and considering this pattern as the outcome of the hypothesized process. This process is then simulated in order to obtain a number of patterns (usually 99 to correspond with conventional significance levels). The same property is then obtained for each of the simulated patterns. We can then examine where the value for the empirical pattern falls within the entire set of 100 values ( 99 from simulated patterns and one from the empirical), thus giving an indication of the likelihood of the empirical pattern occurring under the conditions of the hypothesized process. A more detailed discussion of this testing procedure has been given by Diggle (1979).

Finally, of course, the value of the method will be determined by its ability to enable us to ask and answer more pertinent questions about within-field druml in distribution (Menzies, 1979). To this end, we suggest that it would be valuable to use this method in future comparative studies of drumlins.

\section{ACKNOWLEDGEMENTS}

We should like to thank H. Saunderson and I.J. Smalley for their comments on an earlier draft

$$
\begin{aligned}
& \text { Perpendicular to ice flow } \\
& \text { (azimuth } 225^{\circ} \text { ) } \\
& \text { Phase at E point } \\
& \text { D N } \\
& \begin{array}{llr}
\text { Phase at } D & 1 & 18
\end{array} \\
& {[\mathrm{P}]=\begin{array}{ll}
0.048 & 0.952
\end{array}} \\
& {\left[D_{1}\right]=\quad 0.46 \quad 9.05} \\
& {\left[D_{2}\right]=\quad \begin{array}{rr}
0.92 & 18.08
\end{array}} \\
& x^{2}=0.315
\end{aligned}
$$

of this paper. We are also grateful to P. Schaus, who drafted the figures.

\section{REFERENCES}

Baranowski, S. 1969. Some remarks on the origin of druml ins. Geographia Polonica, Vol. 17, p. 197-208. Canada. Dept. of Energy, Mines and Resources. 1972. Physiography of southern Ontario. [0ttawa], Dept. of Energy, Mines and Resources. Surveys and Mapping Branch. [Scale 1: 1000 000.]

Cliff, A.D., and Ord, J.K. 1981. Spatial processes: models and applications. London, Pion Ltd.

De Vos, S. 1973. The use of nearest neighbor methods. Tijdschrift voor Economische en Sociale Geografie, Deel 64, Af1. 5, p. 307-19.

Diggle, P.J. 1979. Statistical methods for spatial point patterns in ecology. (In Cormack, R.M., and Ord, J.K., ed. Spatial and temporal analysis in ecology. Fairland, Maryland, International Cooperative Publishing House, p. 95-150.)

Diggle, P.J. 1981. Binary mosaics and the spatial pattern of heather. Biometrics, Vol. 37, No. 3, p. 531-39. 
Hill, A.R. 1973. The distribution of drumlins in County Down, Ireland. Annals of the Association of American Geographers, Vol. 63, No. 2, p. 226-40.

Jauhiainen, E. 1975. Morphometric analysis of druml in fields in northern Central Europe. Boreas, Vol. 4, No. 2, p. 219-30.

Kenda11, M.G., and Moran, P.A.P. 1963. Geometrical probability. New York, Hafner Publishing Co.

Menzies, J. 1979. A review of the literature on the formation and location of drumlins. Earth-Science Reviews, Vol. 14, No. 4, p. 315-59.

Miles, R.E. 1964. Random polygons determined by random lines in a plane, I. Proceedings of the National Academy of Sciences, Vol. 52, No. 4, p. 901-07.

Moore, M. 1974. Anisotropically random mosaics. Journal of Applied Probability, Vol. 11, No. 2, p. 37476.

Pielou, E.C. 1964. The spatial pattern of two-phase patchworks of vegetation. Biometrics, Vol. 20, №. 1, p. 156-67.

Pielou, E.C. 1965. The concept of randomness in the patterns of mosaics. Biometrics, Vol. 21, No. 4, p. $908-20$.

Pielou, E.C. 1974. Population and community ecology: principles and methods. New York, Gordon and Breach Scientific Publishers.

Pielou, E.C. [1975.] Ecological diversity. New York, John Wiley and Sons, Inc.

Pielou, E.C. [ $\left.{ }^{C} 1977.\right]$ Mathematical ecology. [Second edition.] New York, John Wiley and Sons, Inc.
Pinder, D.A., and Witherick, M.E. 1972. The principles, practice, and pitfalls of nearest-neighbour analysis. Geography, Vol. 57, Pt. 4, p. 277-88.

Reed, B., and others. 1962. Some aspects of druml in geometry, by B. Reed, C.J. Galvin, Jr, and J.P. Miller. American Journal of Science, Vol.260, №. 3, p. 20010.

Ripley, B.D. 1981. Spatial statistics. New York, John Wiley and Sons, Inc.

Rogers, A. 1974. Statistical analysis of spatial dispersion: the quadrat method. London, Pion Press.

Smalley, I.J., and Unwin, D.J. 1968. The formation and shape of drumlins and their distribution and orientation in druml in fields. Journal of Glaciology, Vol. 7, No. 51, p. 377-90.

Switzer, P. 1965. A random set process in the plane with a Markovian property. Annals of Mathematical Statistics, Vol. 36, №. 6, p. 1859-63.

Trenhaile, A.S. 1971. Drumlins: their distribution, orientation, and morphology. Canadian Geographer, Vol. 15, [No.] 2, p. 113-26.

Trenhaile, A.S. 1975. The morphology of a druml in field. Annals of the Association of American Geographers, Vol. 65, No. 2, p. 297-312.

Vernon, P. 1966. Drumlins and Pleistocene ice flow over the Ards Peninsula/Strangford Lough area, County Down, Ireland. Journal of Glaciology, Vol. 6 , No. 45 , p. 401-09. 